Ilmenau University of Technology

Institute of Economics

Ilmenau Economics Discussion Papers, Vol. 24, No. 118

The Brave New World of Digital Personal Assistants: Benefits and Challenges from an Economic Perspective

Oliver Budzinski, Victoriia Noskova \& Xijie Zhang

December 2018

Institute of Economics

Ehrenbergstraße 29

Ernst-Abbe-Zentrum

D-98 684 Ilmenau

Phone 03677/69-4030/-4032

Fax 03677/69-4203

http://www.wirtschaft.tu-ilmenau.de

ISSN 0949-3859 


\title{
The Brave New World of Digital Personal Assistants: Benefits and Challenges from an Economic Perspective
}

\author{
Oliver Budzinski\#, Victoriia Noskova* \& Xijie Zhang ${ }^{+}$
}

\begin{abstract}
The paper applies economic theories to give an overview of the emerging phenomenon of digital personal assistants (DPAs). A DPA is an intelligent automated system that interacts with the user through a dialogue in natural language, and meanwhile applying third-party services to obtain information and perform various actions. We analyze the benefits of increasing usage of DPAs, such as reduction of transaction costs, enhanced organization efficiency, procompetitive effects, and boosting the e-commerce economy. Besides benefits, however, adopting DPA in life may also contain some risks and downsides, which may reduce the positive welfare effects or even lead to decreasing welfare: biased services, market power on the DPA market and economic dependence on a dominant DPA, potential leveraging of DPA suppliers' market power into neighboring markets, personalized data (ab)use and privacy, media bias and manipulation of public opinion.
\end{abstract}

Keywords: digital personal assistant, DPA, platform economics, economics of privacy, imperfect competition, behavioral economics, antitrust, smart speaker, automated assistant, virtual assistant, digital butler, digital helper, digital assistant, speech-based interface, agent-based assistant, algorithmic assistant, digitization, digital economy

JEL-Codes: L86, L13, L40, D43, D90, D82, K21, 033

\# Professor of Economic Theory, Institute of Economics, Institute of Media and Mobile Communication, Ilmenau University of Technology, Email: oliver.budzinski@tu-ilmenau.de.

Chair for Economic Theory, Institute of Economics, Institute of Media and Mobile Communication, Ilmenau University of Technology, Email: victoriia.noskova@tu-ilmenau.de.

+ Junior researcher, Chair for Economic Theory, Institute of Economics, Institute of Media and Mobile Communication, Ilmenau University of Technology, Email: xijie.zhang@tu-ilmenau.de. 


\section{Introduction}

The existence of information technologies has radically transformed many aspects of modern people's life. As an example of such technology, we can consider a digital personal assistant (DPA), like Apple's Siri, Google Assistant, Microsoft's Cortana, Samsung's Bixby, etc. DPA can help users on various tasks, such as shopping, playing music, setting schedule, sending messages, using household appliances and electronic devices, and offering answers to simple questions, etc., by taking audio or textual orders (Fruend, et al. 2001; Stucke \& Ezrachi 2016; Tractica 2016).

The global market of special home devices with DPA function (smart speakers) is expected to hit US\$2 billion in revenues by 2020, almost a 500 per cent rise over 2015 (Gartner 2016). The number of individual consumer users of DPAs is predicted to increase from 390 million to 1.8 billion worldwide from 2015 to 2021 . Meanwhile, the number of enterprise users is forecasted to grow from 155 million to 843 million (Tractica 2016). Hence, in the nearest future, it is expected that the demand for DPAs will only rise, not only increasingly densely entering into everyday life of ordinary people, but also becoming business solutions in companies.

Considering the potential significant role, which DPA is going to play, the research work on this field suffers from lacking economic scholars' attention at the moment. Papers that shed the spotlight on the topic of DPA are sparse and economic literature is even less. To our best knowledge, the law-and-economics papers by Stucke and Ezrachi $(2016,2018)$, which pointing out both competition issues and consumer welfare issues with DPAs, are the only papers directly addressing economic effects of DPAs. Stucke and Ezrachi also addressed behavioral economic issues by arguing that because of the emotional nature of interactions, trust will be established between users and their DPAs, followed by decisions' delegation from the user to DPA. Next closest studies are focusing on the role of algorithms and their influence on the competition landscape of markets without directly addressing DPAs (Gal \& Rubinfeld 2016, Gal 2018, Schwalbe 2018). As DPAs are also based on (similar) algorithms, the insights from this literature are helpful for our analysis. The rest of the studies about DPAs are from technology development and application points of view. For instance, response correctness and naturality among Siri, Cortana, Google Assistant and Alexa 
is studied by López et al. (2018). DPA's ability and improvement on managing tasks, reminding specific memories and managing calendar are researched widely in recent decade (Yorke-Smith et al. 2009; Yaghoubzadeh et al. 2013; Brewer et al. 2017; Rong et al. 2017). Some researches focused on developing DPAs for helping elderly and cognitive/physical impaired users (Fiol-Roig et al. 2009; Yaghoubzadeh et al. 2013; Costa et al. 2014). Others devoted on specific functions as assisting maintenance of household appliances (Fruend et al. 2001), telling customized stories to children (Adam \& Cavedon 2015), and planning activities aiming to build long-term relationship with users (Coon et al. 2013).

The purpose of this paper is to contribute to filling this gap in literature and explore the emergent market of DPA, the important parties such as DPA suppliers and consumers, the opportunities and problems confronting family, state and society in the coming future. As such, the paper is conceptual in nature and lays out important research problems and programs in this relevant area. In order to serve this purpose, it is organized as follows: in section 2, the definition of DPA and its features are presented. In section 3, the description of DPAs' market is given. In section 4, economic benefits of DPA usage are discussed, whereas section 5 provides the discussion of potential economic challenges. Section 6 concludes.

\section{Definition of Features of DPAs}

Among current researches, which mentioned DPAs or similar concepts, there is no unanimous definition of the term "DPA" since the research field is still on its early stage. The reason is the novelty of the technology and the fact that a unified symbol of these kinds of systems has not yet been formed. Names mentioned in the literature, which can be considered as digital assistants, include intelligent automated assistant (Gruber et al. 2017), intelligent virtual assistant (Lamontagne et al. 2014), virtual personal assistant (Tur et al. 2014), intelligent personal assistant (Canbek \& Mutlu 2016), digital butler, digital helper, digital assistant (Stucke \& Ezrachi 2018), personal digital assistant (Fruend et al. 2001), speech-based natural user interface, voice-activated intelligent personal assistant (López et al. 2018), virtual agent-based daily assistant (Yaghoubzadeh et al. 2013), algorithmic assistant (Gal 2018), etc. 
In order to avoid possible discrepancies, we use the term "digital personal assistant" (DPA), and modified the definition proposed by Gruber et al. (2017). A DPA is an intelligent automated system that interacts with the user through a dialogue in natural language, and meanwhile applying third-party services to obtain information and perform various actions.

DPA is an intelligent system because of its capability of finding information and solutions for a diversity of problems. In technical terms it uses machine-learning algorithms, which are based on the analysis of client's requests and personal data collected by the system to enhance the quality and the individualization of DPA's reactions (Actions on Google 2017; Amazon 2018a). These algorithms also support recommendation functions of different products and services (Amazon 2018b). Their ability in precise and accurate predictions of a user's behavior and preferences is based on the collection of all-dimension data. Setting alarm, arranging calendar and adjusting household appliances automatically involve information of a user's life routine. Playing music, watching videos and doing shopping contains information of his preferences on music genre, video categories and products he purchases, in total giving a comprehensive picture of individual consumption patterns. Because of the ability to provide natural interactive conversation, a DPA can serve its user as a daily life butler, instead of a mere order-taking machine (Sayid 2016; Actions on Google 2017; Amazon 2018a). Hence, a user may prone to be less alert on giving up his personal information with the butler. Moreover, an important characteristic of personal assistants is the nature of their interaction with third-party services, suppliers of music, video content, food, clothes and household appliances, etc., which will also be interested in the data collected by DPA. This state of affairs may have various implications, which are discussed in the next sections.

\section{Markets and Business Models of DPA-Services}

\subsection{The Market of DPAs}

The market development began with the invention of the first DPA (Siri by Apple) in 2011 , which was a part of an operating system for phones, tablets and laptops, etc., providing a hand-free solution to operate with them. Later on, DPAs in different 
forms came to existence: 1) as a pre-installed part of the operating system for different devices ${ }^{1}$, which are owned by or cooperate with the DPA's supplier (Google Assistant by Google, Bixby by Samsung, Cortana by Microsoft, Xiaomi Voice Assistant by Xiaomi, Duer by Baidu, etc.); 2) as an application for different operation systems ${ }^{2}$ and smart speakers, which are produced by the DPA's supplier (Alexa by Amazon, Clova by Line, Kakao I by Kakao, AliGenie by Alibaba, Alice by Yandex, etc.); 3) purely as applications for different operation systems (Hound by SoundHound, Lyra Virtual Assistant by Artificial Solution, etc.). According to publicly available information, in 2017, Amazon (Alexa) was clearly leading the worldwide market with an estimated share of 62 percent, while Google with about 25 percent (Statista 2017). This result could be due to first-mover advantages since Amazon was the first company, which offered smart speaker for its Alexa in 2014 with Google offering its solution in 2016 and Apple following in 2017. Additionally, the business model of Amazon is based on its shopping platform and Google has its long-existing and dominant search engine, so the popularity of these services may contribute to the popularity of 'their' DPA via positive network effects. According to the quoted statistics, the DPA market currently has a duopoly structure (with Amazon's Alexa probably being a dominant supplier) accompanied by a variety of fringe competitors. Notably, the fringe both consists of small and young (innovative) companies and entails solutions by big tech companies with considerable financial power. Therefore, it looks likely that the leading duopolists will experience relevant competitive pressure from fringe competitors despite their currently small market shares.

Generally, market dynamics are still very high since the DPA market is still young and in its turbulent expansion phase. Therefore, it can be expected that the frequency of new market entries will remain significant for the upcoming next years. Moreover, hitherto different applications such as chatbots could be turned into DPAs. Furthermore, some companies focusing their business so far on certain regions (e.g. Xiaomi, Baidu, Alibaba, Yandex) are likely to expand into international markets in the near future. The ongoing technology dynamics make it likely that there will be some maverick competitors among the existing or new-coming market players, considerably 
altering competition dynamics and the market structure. This goes along with expectations that in the near future the range of DPAs' services will be expanded. For instance, all players work on an enlargement of this market. There is increasing attention to smart home technologies, aiming primarily at expanding the ecosystem of DPA-controlled devices. It should be noted that suppliers are interested in ecosystems, in which their devices could exclusively play the main role. This includes, for instance, the possibility for cooperation with automotive suppliers in order to integrate DPA solutions into new cars. ${ }^{3}$

The nature of DPA-services implies that a number of markets are vertically-related or neighboring the DPA-market. For instance, if a DPA is used as an assistant for daily routine or non-routine shopping, then the respective retailing markets become (vertically) interrelated and its effects on the respective product markets become possible. If a DPA is integrated into a smart home or a car, then markets for software services like navigation systems, or markets for goods like heating systems or refrigerators, etc. become neighboring the DPA market. When analyzing the economic effects of DPA-services, the interrelations to these markets matter along with the competition on and the structure of the DPA market itself. In particular, market power of DPAs may negatively influence the competition on such related markets.

\subsection{The Stylized Business Model of DPA-Services}

In regard to many of its functions, in particular the more commercial ones, a DPA may be framed as a digital platform that operates as a two-sided market (see generally on platform economics, inter alia, Rochet \& Tirole 2003, 2006; Armstrong 2006; Evans \& Schmalensee 2007; Haucap \& Heimeshoff 2014; Haucap \& Stühmeier 2016; Budzinski \& Kuchinke 2018). Through its assistance function for consumption and shopping routines, a DPA effectively provides a matching platform for users and third-party suppliers of commodities and services (see Figure 1), each of which offers positive network externalities to the other.

3 At the CES tech show, tech giants have announced that they will add DPAs to new cars. Thus, Nissan and BMW have Microsoft Cortana or Apple's Siri (via CarPlay software) on some models, Ford has a cooperation with Apple and Amazon (Alexa), Hyundai, by its turn, integrated Google Assistant and Apple's Siri in some vehicles, Daimler provides only Google Assistant (Baraniuk 2017). 


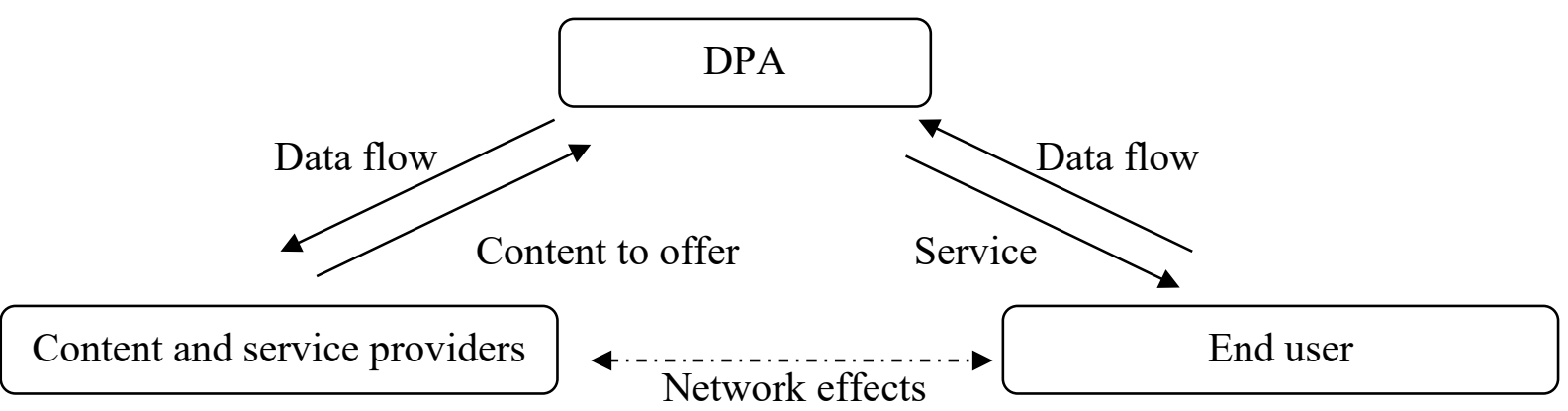

Figure 1: DPA as a platform

Source: adapted from Dewenter \& Rösch (2015, p. 119)

Platforms generally entail the danger that a single company dominates the market. While this may be efficient in terms of allocation, negative dynamic welfare effects, as well as negative static welfare effects from an abusive exercise of the resulting market power may easily overcompensate the allocative benefits. Therefore, competition among platforms is socially desirable but the probability of its sustainable emergence depends on a number of factors. Among such factors increasing the probability of single-firm dominance in platform markets, we should mention strong and/or symmetric indirect network effects (INE), strong direct network effects (DNE), small size of market, supplier-side economies of size, homogeneity of customers' preferences and platform services, incompatibility among platforms (e.g. absence of interconnectivity of users of different platforms), high switching costs, single-homing by consumer/user groups, low innovation dynamics, etc. (inter alia, Haucap \& Heimeshoff 2014; Haucap \& Stühmeiner 2016; Budzinski \& Kuchinke 2018).

DPA as a platform provides strong and symmetric INE because users are interested in high quality of services, and suppliers are interested in access to potential consumers. Consequently, an increase in the number of DPA users for consumption purposes will lead to an increasing number of commodity and service providers wanting to offer their goods via DPA. The other way around, DPA users derive a higher utility of search and recommendation services, entertainment offers and shopping opportunities if more suppliers are available through DPA. Thus, an increasing number of users leads to an increasing amount of suppliers, and vice versa. A mitigating factor may surface when it comes to frequently repeated routine shopping activities where DPA users may actually derive their utility from not-choosing by themselves, so that 
the variety of suppliers may have no effect. A typical variant of commercialization for such platforms would be advertisement, which displays positive INE from platform users to advertisers but often negative INE the other way around. Currently, direct advertising (like advertising breaks) is not part of the business models of DPAs. However, advertisement can also happen indirectly and, for instance, have the appearance of recommendations (which may be biased towards the goods of the advertiser). In such cases, users may not perceive the advertising as manipulating their opinions, thus may not cause negative INE and an outflow of customers. Nevertheless, if advertisement was more intrusive, the negative INEs would be significant. In contrast to INE, DNE should not be strong in DPA markets. Direct network effects arise when the benefit of the users of a platform depends on the number of other users. This is common situation for communication networks (such as social networks, telephone services, messaging services, etc.), where user's utility increase with enlargement of network in which he can interact with others. However, DPA itself does not provide such place of communication among users.

The actual and possible size of the market should not be a restrictive factor as the tasks are diverse and widespread and there is no geographic limitation. If we include potential customers of DPA-services, the estimated market will be large and go across generations. As noted by Stucke \& Ezrachi (2016, p.3), parents started to use technology to care for children and to help themselves at home. Thus, the next generation is integrated into such an environment since childhood. Taking into account the advantages (see section 4), the probability that users will not stop using this type of service increases. While the access to DPA is provided with a device like mobile phone, tablet, laptop and smart speaker nowadays, the developers are attempting to integrate this function in more and more devices, i.e., to build an ecosystem covering an entire house.

The DPA market is characterized by relevant supply-side economies of size. The growth of number of users leads to improvement of the service. The reason is that a DPA platform processing more requests has a bigger database with more variance of users and can better use machine-learning algorithms and data mining to increase its ability to cater various needs from different users. This also enhances the quality 
of its service for each individual user. However, while these economies support market concentration, they will probably not be so strong that only one DPA supplier can exploit them. There will be decreasing returns to a further increasing (historical) database once a certain level of data has been collected. Consequently, every supplier with datasets exceeding a certain minimum volume can be competitive. The competence for sophisticated pooling and analysis of consumer data may become the actual scarce good (Schwalbe 2018). Furthermore, a considerable fixed-cost digression effect (lower average costs of supplying DPA service for each additional consumer) also will favor a concentrated market structure.

Preferences of consumers using DPAs are heterogeneous. One group of them may focus on organizing their smart home, a second group may just use the assistant as an entertainment device, a third group may predominantly need an assistant for calendar and travel organization, etc. For instance, it is conceivable that some users would never use their DPAs for shopping purposes because they enjoy shopping themselves. Others may be happy to get rid of routine shopping but keep doing the extraordinary consumption (for example, fashion, holidays, furniture, cars) themselves - and even others may be happy to rely fully on a DPA shopping service. Consequently, there exists a possibility of specialization for DPA suppliers. If the quality of service provided by companies will be different for different DPAs' functions, then different types of consumers will use various DPAs creating scope for specialized offers. However, the fundamental idea of any DPA is interaction with its user in a native way and finding solutions for a fundamentally open-ended diversity of problems. Thus, this fact may imply that comprehensive services thrive, rather than specialized solutions, rendering the competition-enhancing effect of heterogeneous preferences rather ineffective.

The nature of a DPA as a comprehensive assistant to all personal needs should point to single-homing on the side of the users. However, on the market side of commodities, services and content providers incentives for multi-homing are strong, so that all consumers can be reached irrespective of which DPA they are using. Thus, if multihoming is not strategically (artificially) limited for anticompetitive purposes by a DPA, third-party providers will strive to multi-home. 
Another factor in this market are innovation dynamics. Currently, innovation dynamics are very high in the market as it is still a very young technology-driven market. This is a procompetitive factor as long as DPAs have not reached a more mature level of technology. After that, it is possible that big companies will slow down the output of innovative products in order to get the most from the previous innovations.

According to these elements of the DPA market, the economic forces driving this market towards a (quasi-) monopolistic structure (i.e. single-firm dominance) are not too strong and countervailed by other factors. Thus, from the nature of the DPA market, sustainable competition among several DPA service suppliers should be possible. Due to the factors favoring company size, the structure of a narrow oligopoly, i.e. competition among few DPA-platforms, appears to be more likely in future than competition among a multitude of suppliers. This result does not preclude companies from trying to actively monopolize this market. However, if this happens, competition policy must step in and prevent a tipping of this market into single-firm dominance or a quasi-monopolistic structure. In order to further assess the welfare effects of DPA-services, we now focus more closely on the economic benefits (section 4) and challenges (section 5) from DPAs.

\section{Benefits of DPAs}

Despite of their inconsequential nature, mundane daily tasks take our time and efforts. With DPAs functioning as human-like butlers, users can benefit from several aspects by relinquishing daily chores to them.

The first beneficial effect from using a DPA is a significant reduction of transaction costs. With a voice-command feature looking for information with DPA is quicker and easier than typing requests and searching on internet by users' own. As a result, information-searching cost is significantly lowered. Since DPA functions are based upon personal data, their algorithms try to predict users' preferences (Linden et al. 2003) and adjust search results accordingly. Obviously, accuracy of preference approximation depends on the richness and quality of available user data. With rich consumer behavior data, accuracy will increase tremendously. This phenomenon is well-known from databased internet platforms like Google's search engine, who 
once became market leader due to providing more accurate (to the individual preferences) search results than its competitors.

Furthermore, consumer welfare may be promoted by increasing information about consumption options that the user otherwise would not detect. For instance, Amazon's success to a considerable extent derives from superior databased search and recommendation services compared to its traditional competitors (Budzinski \& Köhler 2015). Regarding streaming platforms like Netflix, it is commented "The algorithms know you better than you know yourself". This comment was given by Xavier Amatrian, former Netflix data scientist as the number of users increased significantly after the platform started to give recommendations basing on algorithms, instead of letting users plan their watching schedule by themselves (Lebowitz 2017). DPAs have the potential to further enhance these benefits by basing their recommendations on more and better personal data, and by being available and accessible more directly and more ubiquitously. By taking accurate individualized suggestions, users' decision-making cost can be reduced immensely.

Besides reduced information-searching cost and decision-making cost, transaction cost can be lowered also in other ways. As voice input is faster than keyboard input, it sets up an opportunity for parallelization of work, facilitating users' multi-tasking, which makes their life more efficient. Functions of DPAs providing control of smart home devices, calendar management, entertainment, etc. will enable consumers to spend less time to perform these actions. Moreover, because communication with a DPA does not require any special knowledge or skills (the only requirement is the ability to maintain a conversation), which allows interaction with them without any difficulties, children, elderly people and people with disabilities can access different services more easily than before (Fiol-Roig et al. 2009; Yaghoubzadeh et al. 2013; Costa et al. 2014).

A second benefit could be enhanced organization efficiency. By replacing personal secretaries with DPAs in organizations, which can be able to work faster and longer than humans, i.e., 24 hours per day and seven days per week, many of the repetitive and administrative tasks can be finished a lot quicker. Additionally, wage cost will be lowered, since this means there will be less need to hire human secretaries. As a 
result, organization performance will be improved. Moreover, as DPAs either come together with existing devices or are easily portable, locations of the tasks will not be a problem anymore. Hence, organizations' economic activities can benefit from using DPA as a secretary creating positive growth effects on the economy. ${ }^{4}$

Thirdly, there is a procompetitive effect. It is worth mentioning that this service can find the best offers for consumers via algorithms. This conclusion is based on considering the decision-making features of the digital assistant. So, it far surpasses a human not only in terms of the amount of information that can be taken into account when preparing a solution, but also by higher speed of data processing. This allows DPAs to analyze over the same period of time more options for solving the problem, which significantly improves the quality of the final solution (in other words, the probability to make a better decision increases). By increasing market transparency, the use of an assistant may lead to a reduction of searching cost, consumer biases and help to avoid marketing manipulation efforts of suppliers (Nowag 2016; Gal 2018; Gal \& Elkin-Koren 2017; Mehra 2017). This situation creates procompetitive effects among stores, which are forced to provide better prices and quality to customers (Gal \& Rubinfeld 2016; Mehra 2017), further enhancing the users' welfare.

A more far-reaching implication would be that DPAs make better decisions than the user himself not only by providing more information but also by "knowing better" than the user. For instance, Gal (2018) argues that the black box character of the DPA algorithm-based decision helps to avoid biases that would taint the optimal decision when done by the user himself. The exact working properties of the algorithm (using its information processing power to best guess the preferences of its user) are unknown for the user, which may be understood to be a more objective interpretation of the users' preferences than the human user can do by himself. So, there are no any biases influencing an objective decision-making (Gal 2018). However, if decisions by a DPA are assessed to be superior to human consumer decision,

4 A lower demand of human secretaries at the labor market is likely to be overcompensated by increasing labor demand in the context of supplying and maintaining DPA-services as well as by the growth effects. However, notwithstanding, in a sclerotic labor market with significant involuntary unemployment, it may come along with temporary labor market frictions. 
this clearly departs from methodological individualism, i.e. from the notion that the individual is the only source for his wants and needs - and consequently from the paragon that each individual has the right to make his own decisions. Thus, it creates significant scope to manipulate and overrule consumers in the name of various commercial and political interests, injected into that black box. So, from an economics perspective, this welfare promise is doubtful at best (see also section 5).

Fourthly, DPAs may boost the e-commerce economy. As a DPA allows a user to conduct tasks by daily dialogs, it will ease online shopping by skipping a number of complex ordering and billing steps, which have prevented certain consumer groups from buying goods or ordering services online. With the popularization of DPAs, more consumer groups may turn towards e-commerce. Thus, DPAs may have a stimulating effect on the e-commerce economy. If the growth in e-commerce overcompensates losses for traditional business, i.e. there are additional transactions and not only shifts from off- to online, then this boosts the overall economy and consumer welfare.

\section{Challenges from DPAs}

Besides benefits, however, adopting DPAs in life may also contain some risks and downsides, which may reduce the positive welfare effects or even lead to decreasing welfare from an economics perspective. Consumer behavior considerably matters for the welfare effects as does the workability of competition in the market for DPAs and related markets. If users are assumed to be perfectly informed and to be acting hyper-rationally with DPAs competing on a poliopolistic, contestable and non-integrated market, then the scope for negative welfare effects from DPAs is virtually zero. However, modern economics have long departed from such a simplistic behavioral model due to its lack of empirical reliability in many cases as it has departed from assuming "perfect competition"-markets. Instead, boundedly-rational or naïve consumers use limited cognitive capabilities to deal with incomplete and distorted information. They are susceptible to emotions, external environment and different biases, and decision-making of which deviates from expected utility theory (Jolls et al. 1998; Kaufman 1999). Consequentially, behavioral limitations along with imperfection and 
asymmetries of information offer a scope for DPA-services exploiting consumers. Furthermore, oligopolistic market structures or even single-firm dominance in the market for DPAs as well as vertically and conglomerately integrated companies enhance the scope for anticompetitive strategies reducing consumer welfare. Under this condition, the risks DPAs may bring come to existence. We categorize these potential risks into five directions.

Firstly, biased services. Boundedly rational or naïve users may develop trust in their digital butlers more easily and through different ways than sophisticated users. While with traditional webpage-based e-commerce it still leaves consumers the necessity to search and read information on their own, voice-controlled DPAs may easily become an information gate-keeper for boundedly rational or naïve users. Under this situation, DPAs are likely to be employed to induce their customers' purchasing behavior according to the interests of their suppliers. In the case that DPAs recommend products of their own subsidiaries or business partners and at the same time ostensibly matching customers' preferences, in contrast with super-rational consumers, naïve consumers may tend to simply rely on their butlers' suggestions or even relinquish their decision rights to the DPAs without further concerns. Moreover, imperfection and asymmetries of information may prevent even more rational consumers, i.e. "principals", from exercising sufficient control over their digital "agents", which also creates a scope for DPA suppliers to make DPAs suit their business interests at the expense of the user's welfare. Since DPAs function based upon individualized data and algorithm, the hidden agenda may be difficult to detect. This may be aggravated if users get locked-in to the services of a given DPA, i.e. switching to another DPA becomes disincentivized. For instance, DPA-suppliers may block the transferability or portability of data among different assistants for strategic reasons, so that users must spend significant additional time and effort on training a new assistant (in this situation, time and effort represent switching costs). On the side of the users, such incompatibilities among different DPAs increase switching costs and, thus, cause lock-ins (dependence on one supplier).

Secondly, market power of a dominant DPA. The DPA market has the same features like many others digital platforms. In particular, as it's mentioned in section 3, the current DPA ${ }^{\text {market }}$ is a duopoly market with various fringe competitors. The incumbent 
players build strategies, targeting on each expanded field (e.g., the development of smart speakers, the integration of DPAs with cars). The contestability of the market is hampered by the presence of entry barriers, supported by network effects, supplier-side economies of size, incompatibility among platforms, switching costs, intellectual property law and ability to investment which associates with the scale of research and development costs. The high possibility that the market for DPAs will display a rather narrow oligopoly structure in coming future is not necessarily a problem, as long as competition intensity among the oligopolists remains strong. Notwithstanding, if the number of relevant competitors becomes very narrow, incentives to enter into a collusive equilibrium (so-called coordinated effects) increase and DPAsuppliers may coordinate their behavior by means of tacit collusion or cartel-like structures instead of competing with each other - at the cost of consumer welfare. Furthermore, if the market tips into a monopoly-like structure with one dominant supplier - be it by strategic monopolization efforts from one company or through other avenues - then the dominant DPA experiences scope for (i) exploit the dependency of consumers by increasing prices and/or reducing service quality as well as (ii) exploit the economic dependency of third-party suppliers, who require access to the DPA (and its search, recommendation, and decision-making services) in order to have access to a relevant number/share of consumers. If one DPA becomes an essential gatekeeper, for instance for shops or content and service providers, to reach their customers or audience, like the Google search engine or Amazon currently tend to be for online shopping (Bougette et al. 2018), it can force unfair conditions upon them and appropriate considerable parts of their economic margins and rents.

Thirdly, potential leveraging of DPA suppliers' market power into neighboring markets. If DPA suppliers enjoy market power, then they may use it to discriminate amongst third-party services (music and video streaming services, shops, etc.) in order to favor their own activities in these markets through either subsidiaries or partner companies. In the case of goods providers, this would imply that a consumer using a specific DPA cannot buy from shop A but only from shop B (so that shop A cannot get access to the users of this DPA). As a result, access to the DPA becomes important for being able to compete on the neighboring markets of the goods that are searched for, recommended or shopped via it. If suppliers of such products are 
either integrated with the DPA supplier or if the two form a collusive arrangement, then incentives to foreclose this part of the market surface - and the market power from the DPA market may be leveraged onto the related goods' market. For instance, if users organize their routine shopping via Amazon's Alexa, this may be bundled with buying from Amazon's (online and offline ${ }^{5}$ ) stores. Similarly, search results and recommendations may favor products and offers through Amazon's shops. Amazon owning the DPA and retailing shops represents a vertical integration, if the DPA is viewed to be a part of the supply-chain. If the two markets are viewed to be distinctive then such scenario is considered as conglomerate integration. In any case, under the aforementioned conditions, anticompetitive effects become possible with negative consumer welfare consequences. Similar effects follow from a collusive arrangement like Google (with its DPA Google Assistant) and Walmart entering in the U.S (Lore 2017). In these scenarios, the combination of biased services and foreclosure may create significant negative welfare effects.

Fourthly, personalized data (ab) use and privacy. Close interaction between user and DPA enables a huge amount of user data accumulation. The welfare effects of using personalized data are controversial and crucially depend on the underlying scenario (inter alia, Taylor 2004; Acquisti \& Varian 2005; Acquisti et al. 2016; Brown 2016; Kerber 2016; Budzinski \& Kuchinke 2018; Budzinski \& Stöhr 2018). The naturally close relation between a user and his DPA implies privacy concerns. In general, there should be no problem as long as the personal data is used to improve the DPA service and the user is well-informed about the data usage (Acquisti \& Varian 2005). However, if users experience information deficiencies about the use of their personal data, DPA suppliers may gain a scope for employing consumer welfare-reducing strategies (Taylor 2004; Acquisti \& Varian 2005; Hermalin \& Katz 2006). This includes data trading, i.e. the DPA supplier sells the collected personalized data to third parties without users' knowledge, consent, and participation in revenue. Similarly, the DPA supplier and his subsidiaries themselves may employ the personalized data for purposes outside the DPA service itself. Eventually, the device may collect data from sources the

Amazon has recently bought the U.S. supermarket chain Whole Foods and, in a parallel movement, opened its own supermarket in the U.S. (Amazon 2017; The Guardian 2018). 
user is not aware of. ${ }^{6}$ Resulting consumer-harming strategies may involve increasing advertising attacks (target advertising, but also spamming) on the user (Hui \& Png 2006; Anderson \& de Palma 2012; Hoffmann et al. 2014) or price discrimination from other services where the user cannot expect them to be based on his personal data (Heidhues et al. 2016; Heidhues \& Köszegi 2017). In addition to strategically misleading information of users, empirical research on commercial internet platforms shows that users often ignore provided information on data usage terms and conditions (Obar \& Oeldorf-Hirsch 2018). Reasons include incomprehensible and extensively long terms and conditions (often due to legal requirements ${ }^{7}$ ) as well as a lack of choice and alternatives, i.e. less-data-intrusive options in the market (because of insufficient competition), perhaps combined with a higher monetary price. Furthermore, naïve users may simply act overly trustful. It is likely that these insights fit into DPA scenarios as well, with naïve trustfulness perhaps playing an even bigger role due to the interaction/communication effect. Another issue relates to the risk of data theft. As a number of economic agents are interested in this kind of data, it can cause serious issues, e.g. information leakage. Since such interest will only grow in the future, the security of personal data is incrementally important.

Fifth, media bias and manipulation of public opinion. Personalized data can also be employed to influence or manipulate political opinions of users. For instance, a recent scandal linked the outcome of political elections in the United States with advertising on Facebook based upon (leaked or even stolen) personalized data of users (Rosenberg et al. 2018). This example can serve as a warning of potential capability of platforms forming beliefs and values of users by providing different features and recommendations. Detection of a similar act in DPA usage may be even more difficult than in any cases of social network like Facebook. While this new type of media bias concern entails many non-economic dimensions, it may also include relevant welfare aspects for society.

6 This is the core of the German Facebook antitrust case, alleging that Facebook collects user data from third party applications, pooling them with their own personalized data (Bundeskartellamt 2017).

7 Some of this is caused by (so-called) consumer protection laws. 


\section{Conclusion and Further Research}

With the rapid development of new technologies, our life is influenced and daily habits are changed bit by bit. Emergent products like DPAs, which aim to perform as intelligent butlers helping consumer's daily life from entertainment to work, from controlling household appliances to shopping, determine to gain users' trust on all sorts of problems and tasks in life and become the bridge between consumers and all other third-party service providers. On one hand, modern life can enjoy the convenience, lower-cost and improved efficiency DPAs bring. On the other hand, it can also pose significant challenges and risks that we must be alert to.

DPA usage entails concerns of potential market power (also in neighboring markets) and the subsequent negative effects on welfare. DPAs, on one side, reduce consumers' information-searching and decision-making costs, possess the potential to encourage and intensify competition on goods markets at the benefit of consumers, as well as, may contribute to optimizing decision-making. On the other side, they create a scope for abusing personalized data and privacy, restricting competition at the expense of consumers, and public opinion manipulation. Thus, a widespread use of DPAs would not per se be positive or negative from an economics perspective. Instead, it depends on the features and characteristics of (i) DPA market and (ii) consumer behavior, whether the benefits will dominate or the disadvantages may prevail.

(i) Effective competition on the DPA market plays a crucial role. Most challenges and possible negative effects from DPAs are associated with market power on the DPA market. As long as a single DPA supplier or a collusive collective of few DPA suppliers dominates the market, both users (including business customers and consumers) and third-party suppliers will become dependent on their DPA supplier: customers' choice, then, is restricted to using a DPA or not at all (because of lacking competitive alternatives) and third-party suppliers will see the access to the DPA as a platform as an essential condition for doing business. Given that both customers and third-party suppliers can choose and switch among different, competing DPAs, any abuse of the DPA central position towards customers or 
third-party suppliers have to confront a strong reaction, which leads to negative effects on its own business. Nevertheless, if there is virtually no competition among DPA suppliers, the dominant one wins the scope for abusing the locked-in customers and third-party suppliers and may even leverage its market power into upstream markets.

(ii) Additionally, consumer behavior and its rationality considerably impact the welfare effects of DPAs. Under the circumstance when consumers are fully rational and vigilant towards their DPAs, services of DPAs should be welfare-increasing in most of the cases. However, if consumers behave boundedly-rational or naïve with their DPAs, it is doubtful whether the challenges we discussed can be offset by the benefits DPAs deliver. While it is an empirical question how rational or how naïve, respectively, users of DPAs behave, the daily-life situations are more likely to entail relevant elements of the second scenario. In contrast, very trustful users would increase the scope of DPA suppliers to exploit consumers - to some degree even despite intense competition.

Obviously, a combination of market power and naïve consumer represent the most problematic scenario, whereas effective competition and smart users would most likely suffice to comprehensively limit negative effects.

As a consequence, protecting competition in the DPA market and combating concentration strategies (through mergers and acquisitions but also through entry deterrence, raising rivals' costs and other deterrence strategies towards smaller competitors or strategic monopolization) by the means of an active competition policy represents an important regulatory precondition for reaping the benefits of DPAs. In contrast to conventional wisdom regarding many traditional markets, vertical integration and conglomerate power are very likely to cause negative welfare effects by changing the incentive structures in the markets. Competition authorities need to address the already visible issues in this regard. Since limited the scope for market power is difficult to fully avoid in the DPA market due to its economic characteristics (see section 3), the problem of economic dependence, exceeding the narrower understandings of abuse of market power prevalent in recent decades' competition policy, is of vital importance and needs to be actively and effectively addressed (as in 
the digital economy in general: Bougette et al. 2018; Budzinski \& Stöhr 2018). Moreover, the enforcement of compatibility and inter-operability may be of particular prominence in the DPA market.

While the tools for an effective antitrust policy are available (and 'just' need to be strictly employed), user behavior is more difficult to regulate or police. Consumer protection policy may attempt to make users better informed and behave more rationally by information campaigns - but whether this is enough remains doubtful at the least when looking at such phenomena as the privacy paradox or at the implications of modern behavioral economics researches. Additionally, data policies may be rigorously regulated ${ }^{8}$ as an element of consumer protection policy and justified by the bounded-rational character of consumer behavior in this market. Notwithstanding the benefits of privacy protection, it must be noted that also the benefits of DPAs rely on an extensive collection and use of personalized data, which in itself may limit the possibility of combating the cons while keeping the pros of a widespread DPA employment.

Shaping an appropriate institutional framework for DPAs, however, requires further knowledge about the (anti-)competitive interrelations and strategies among the market players as well as, about the dependence of user behavior on the characteristics of their interaction with the DPA. The existing literature on the economics of commercial online platforms provides first insights that need to be specified and deepened. Among the research issues that need to be tackled, we want to emphasize the following: (i) how rational the users tend to behave with their DPAs and what are the influencing factors of various types of non-rational consumer behavior, (ii) which kinds of competition situation and company structures ((absence of) vertical and conglomerate integration) frustrate anticompetitive incentives in the DPA and in neighboring markets, (iii) which institutional framework best reaps the efficiencies of commercially employing personalized data without exploiting DPA users and ensuring their data security. Further researches are necessary to provide suitable answers to these questions, which helps to deal with the possible challenges from DPAs

8 Regulations can be, inter alia, data policy transparency, artificial barriers reduction, compatibility of the algorithms. See Gal (2018). 
as a specific type of digital innovation dynamics with the potential to considerably change our daily life.

\section{References}

Acquisti, A. \& Varian, H. R. (2005), "Conditioning Prices on Purchase History", Marketing Science, Vol. 24 No. 3, pp. 367-381.

Acquisti, A., Taylor, C. R. \& Wagman, L. (2016), "The Economics of Privacy", Journal of Economic Literature, Vol. 54 No. 2, pp. 442-492.

Actions on Google (2017), "The Conversational UI and Why It Matters", available at: https://developers.google.com/actions/design/ (accessed 18 March 2018).

Adam, C. \& Cavedon, L. (2015), “Once upon a time... a companion robot that can tell stories", [Research Report] RR-LIG-051, LIG. 2015. 〈hal-01307954〉, available at: https://hal.archives-ouvertes.fr/hal-01307954 (accessed 11 April 2018).

Amazon (2017), "Amazon to acquire whole foods market", available at: https://press.aboutamazon.com/news-releases/news-release-details/amazonacquire-whole-foods-market (accessed 13 April 2018).

Amazon (2018a), “Learn Alexa voice service”, available at: https://developer.amazon.com/alexa-voice-service/learn (accessed 18 March 2018).

Amazon (2018b), "Voice shopping", available at: https://www.amazon.com/alexavoice-shopping/b?ie=UTF8\&node=14552177011 (accessed 18 March 2018).

Anderson, S. P. \& de Palma, A. (2012), "Competition for attention in the information (overload) age", RAND Journal of Economics, Vol. 43 No. 1, pp. 1-25.

Armstrong, M. (2006), "Competition in two-sided markets", RAND Journal of Economics, Vol. 37 No. 3, pp. 668-691.

Baraniuk, C. (2017), "CES 2017: Car-makers choose virtual assistants", available at: http://www.bbc.com/news/technology-38526807 (accessed 10 May 2018).

Bougette, P., Budzinski, O. \& Marty, F. (2018), “Exploitive abuse and abuse of economic dependence", Updated Version, IImenau economics discussion papers, Ilmenau University of Technology, Ilmenau, December 2018. 
Brewer, R. N., Morris, M. R. \& Lindley, S. E. (2017), "How to remember what to remember: exploring possibilities for digital reminder systems", in Proceedings of the ACM on interactive, mobile, wearable and ubiquitous technologies, Vol. 1 No. 38.

Brown, I. (2016), "The economics of privacy, data protection and surveillance", in Bauer, J. \& Latzer, M. (Ed.), Handbook on the Economics of the Internet, Edward Elgar, Cheltenham, pp. 247-261.

Budzinski, O. \& Köhler, K. H. (2015), "Is Amazon the next Google?", ORDO, Vol. 66, pp. 263-288.

Budzinski, O. \& Kuchinke, B. A. (2018), "Modern industrial organization theory of media markets and competition policy implications", IImenau economics discussion papers [115], Ilmenau University of Technology, Ilmenau, September 2018.

Budzinski, O. \& Stöhr, A. (2018), “Competition policy reform in Europe and Germany - institutional change in the light of digitization", IImenau economics discussion papers [117], Ilmenau University of Technology, Ilmenau, November 2018.

Bundeskartellamt (2017), "Preliminary assessment in Facebook proceeding: Facebook's collection and use of data from third-party sources is abusive", Press release, Bonn, 19 December 2017.

Canbek, N. G. \& Mutlu, M. E. (2016), “On the track of artificial intelligence: Learning with intelligent personal assistants", Journal of Human Sciences, Vol. 13 No. 1, pp. 592-601.

Coon, W., Rich, C. \& Sidner, C. L. (2013), "Activity planning for long-term relationships", in Proceedings of intelligent virtual agents: 13th international conference, IVA 2013, Edinburgh, UK, August 29-31, 2013, Springer, Vol. 8108.

Costa, N., Domingues, P., Fdez-Riverola, F. \& Pereira, A. (2014), "A mobile virtual butler to bridge the gap between users and ambient assisted living: A smart home case study", Sensors, Vol. 14 No. 8, pp. 14302-14329.

Dewenter, R. \& Rösch, J. (2015), “Einführung in die neue Ökonomie der Medienmärkte", Springer Gabler, Wiesbaden. 
Evans, D. S. \& Schmalensee, R. (2007), "The industrial organization of markets with two-sided platforms", Competition Policy International, Vol. 3 No. 1, pp. 151179.

Fiol-Roig, G., Arellano, D., Perales, F. J., Bassa, P. \& Zanlongo, M. (2009), “The intelligent butler: A virtual agent for disabled and elderly people assistance", in International Symposium on Distributed Computing and Artificial Intelligence 2008 (DCA/ 2008), Springer, Berlin, Heidelberg, pp. 375-384.

Fruend, J., Geiger, C., Grafe, M. \& Kleinjohann, B. (2001), "The augmented reality personal digital assistant", in Proceeding of 2nd international symposium on mixed reality, pp. 145-146

Gal, M. S. \& Elkin-Koren, N. (2017), "Algorithmic consumers", Harvard Journal of Law and Technology, Vol. 30, pp. 309-353.

Gal, M. S. \& Rubinfeld, D. L. (2016), “The hidden costs of free goods: Implications for antitrust enforcement", Antitrust Law Journal, Vol. 80 No. 3, pp. 521.

Gal, M. S. (2018), "Algorithmic challenges to autonomous choice", Michigan Telecommunications and Technology Law Review, forthcoming.

Gartner (2016), "Gartner says worldwide spending on VPA-enabled wireless speakers will top $\$ 2$ billion by 2020", available at: https://www.gartner.com/newsroom/id/3464317 (accessed 2 February 2018).

Gruber, T. R., Cheyer, A. J., Kittlaus, D., Guzzoni, D. R., Brigham, C. D., Giuli, R. D., Bastea-Forte, M. \& Saddler, H. J. (2017), "Intelligent automated assistant", U.S. Patent 9,548,050.

Haucap, J. \& Heimeshoff, U. (2014), “Google, Facebook, Amazon, eBay: Is the internet driving competition or market monopolization?", International Economics and Economic Policy, Vol. 11 No. 1, pp. 49-61.

Haucap, J. \& Stühmeier, T. (2016), "Competition and antitrust in internet markets", in: Bauer, J. \& Latzer, M. (Ed.), Handbook on the Economics of the Internet, Edward Elgar, Cheltenham, pp. 183-210.

Heidhues, P. \& Köszegi, B. (2017), "Naivete-based discrimination”, The Quarterly Journal of Economics, Vol. 132 No. 2, pp. 1019-1054.

Heidhues, P., Köszegi, B. \& Murooka, T. (2016), “Inferior products and profitable deception", The Review of Economic Studies, Vol. 84 No. 1, pp. 323-356. 
Hermalin, B. E. \& Katz, M. L. (2006), “Privacy, property rights and efficiency: The economics of privacy as secrecy", Quantitative Marketing and Economics, Vol. 4 No. 3, pp. 209-239.

Hoffmann, F., Inderst, R. \& Ottaviani, M. (2014), "Persuasion through selective disclosure: Implications for marketing, campaigning, and privacy regulation", Working Paper.

Hui, K.-L. \& Png, I. P. L. (2006), "The economics of privacy", in Hendershott, T. (Ed.), Economics and Information Systems, Vol. 1, Elsevier, Amsterdam, pp. 1-23.

Jolls, C., Sunstein, C. R. \& Thaler, R. (1998), "A behavioral approach to law and economics", Stanford Law Review, pp. 1471-1550.

Kaufman, B. E. (1999), "Emotional arousal as a source of bounded rationality", Journal of Economic Behavior \& Organization, Vol. 38 No. 2, pp. 135-144.

Kerber, W. (2016), "Digital Markets, data, and privacy: Competition law, consumer law and data protection", Journal of Intellectual Property Law \& Practice, Vol. 11 No. 11, pp. 856-866.

Lamontagne, L., Laviolette, F., Khoury, R. \& Bergeron-Guyard, A. (2014), "A framework for building adaptive intelligent virtual assistants", in Proceeding of the 13th IASTED international conference on artificial intelligence and applications, pp. 17-19.

Lebowitz, S. (2017), "A former Google data scientist explains why Netflix knows you better than you know yourself", available at: https://www.businessinsider.in/A-former-Google-data-scientist-explains-why-Netflix-knowsyou-better-than-you-know-yourself/articleshow/58964661.cms (accessed 29 March 2018).

Linden, G., Smith, B. \& York, J. (2003), “Amazon.com recommendations: Item-toitem collaborative filtering", IEEE Internet Computing, Vol. 7 No. 1, pp. 7680.

López G., Quesada L. \& Guerrero L. A. (2018), “Alexa vs. Siri vs. Cortana vs. Google Assistant: A comparison of speech-based natural user interfaces", in International conference on applied human factors and ergonomics, Springer, Cham, pp. 241-250. 
Lore, M. (2017), “Walmart, Google partner to make shopping even easier - Here's how", available at: https://blog.walmart.com/innovation/20170823/walmartgoogle-partner-to-make-shopping-even-easier-heres-how (accessed 28 March 2018).

Mehra, S. K. (2017), “Robo-seller prosecutions and antitrust's error-cost framework", Antitrust Chronicle, Vol. 2 No. 37.

Nowag, J. (2016), "The UBER-cartel? UBER between labour and competition law", European and Competition Law Lund University, Vol 3.

Obar, J. \& Oeldorf-Hirsch, A. (2018), "The biggest lie on the internet: Ignoring the privacy policies and terms of service policies of social networking services", Information, Communication \& Society, pp.1-20.

Rochet, J. C. \& Tirole, J. (2003), "Platform competition in two-sided markets", Journal of the European Economic Association, Vol. 1 No. 4, pp. 990-1029.

Rochet, J. C. \& Tirole, J. (2006), "Two-sided markets: A progress report", RAND Journal of Economics, Vol. 37 No. 3, pp. 645-667.

Rong, X., Fourney, A., Brewer, R. N., Morris, M. R. \& Bennett, P. N. (2017), “Managing uncertainty in time expressions for virtual assistants", in Proceedings of the $2017 \mathrm{CHI}$ conference on human factors in computing systems, ACM, pp. 568579.

Rosenberg, M., Confessore, N. \& Cadwalladr, C. (2018), “How trump consultants exploited the Facebook data of millions", available at: https://www.nytimes.com/2018/03/17/us/politics/cambridge-analytica-trump-campaign.html (accessed 29 March 2018).

Sayid, R. (2016), "Google's virtual butler will obey your commands, from turning on music to ordering flowers", available at: http://www.mirror.co.uk/tech/googles-virtual-butler-obey-your-8007531 (accessed 24 August 2017)

Schwalbe, U. (2018), "Algorithms, machine learning, and collusion", discussion paper, Universität Hohenheim, Hohenheim, August 2018.

Statista (2017), "Global intelligent assistant market share 2017 and 2020", available at: https://www.statista.com/statistics/789633/worldwide-digital-assistantmarket-share/ (accessed 20 March 2018). 
Stucke, E. M. \& Ezrachi, A. (2016), "Is your digital assistant devious?", University of Tennessee Legal Studies research paper [304], University of Tennessee Legal Studies, Tennessee, August 2016.

Stucke, E. M. \& Ezrachi, A. (2018), "How your digital helper may undermine your welfare, and our democracy", Berkeley Technology Law Journal, Vol. 32 No. 3, pp. 1239-1299.

Taylor, C. R. (2004), "Consumer privacy and the market for customer information", RAND Journal of Economics, Vol. 35 No. 4, pp. 631-651.

The Guardian (2018), "Amazon's first checkout-free grocery store opens on Monday", available at: https://www.theguardian.com/business/2018/jan/21/amazonsfirst-automated-store-opens-to-public-on-monday (accessed 13 April 2018).

Tractica (2016), "The virtual digital assistant market will reach $\$ 15.8$ billion worldwide by 2021", available at: https://www.tractica.com/newsroom/press-releases/the-virtual-digital-assistant-market-will-reach-15-8-billion-worldwideby-2021/ (accessed 13 December 2017).

Tur, G., Deoras, A. \& Hakkani-Tür, D. (2014), “Detecting out-of-domain utterances addressed to a virtual personal assistant", in 15th annual conference of the international speech communication association, pp. 283-287.

Yaghoubzadeh, R., Kramer, M., Pitsch, K. \& Kopp, S. (2013), "Virtual agents as daily assistants for elderly or cognitively impaired people", in International workshop on intelligent virtual agents, Springer, Berlin, Heidelberg, pp. 79-91.

Yorke-Smith, N., Saadati, S., Myers, K. L. \& Morley, D. N. (2009), "Like an intuitive and courteous butler: A proactive personal agent for task management", in Proceedings of the 8th international conference on autonomous agents and multiagent systems, Vol. 1, pp. 337-344. 


\section{Diskussionspapiere aus dem Institut für Volkswirtschaftslehre der Technischen Universität IImenau}

Nr. 69 Budzinski, Oliver: Empirische Ex-Post Evaluation von wettbewerbspolitischen Entscheidungen: Methodische Anmerkungen, Januar 2012.

Nr. 70 Budzinski, Oliver: The Institutional Framework for Doing Sports Business: Principles of EU Competition Policy in Sports Markets, January 2012.

Nr. 71 Budzinski, Oliver; Monostori, Katalin: Intellectual Property Rights and the WTO, April 2012.

Nr. 72 Budzinski, Oliver: International Antitrust Institutions, Juli 2012.

Nr. 73 Lindstädt, Nadine; Budzinski, Oliver: Newspaper vs. Online Advertising - Is There a Niche for Newspapers in Modern Advertising Markets?

Nr. 74 Budzinski, Oliver; Lindstädt, Nadine: Newspaper and Internet Display Advertising - Co-Existence or Substitution?, Juli 2012b.

Nr. 75 Budzinski, Oliver: Impact Evaluation of Merger Control Decisions, August 2012.

Nr. 76 Budzinski, Oliver; Kuchinke, Björn A.: Deal or No Deal? Consensual Arrangements as an Instrument of European Competition Policy, August 2012.

Nr. 77 Pawlowski, Tim, Budzinski, Oliver: The (Monetary) Value of Competitive Balance for Sport Consumers, Oktober 2012.

Nr. 78 Budzinski, Oliver: Würde eine unabhängige europäische Wettbewerbsbehörde eine bessere Wettbewerbspolitik machen?, November 2012.

Nr. 79 Budzinski, Oliver; Monostori, Katalin; Pannicke, Julia: Der Schutz geistiger Eigentumsrechte in der Welthandelsorganisation - Urheberrechte im TRIPS Abkommen und die digitale Herausforderung, November 2012.

Nr. 80 Beigi, Maryam H. A.; Budzinski, Oliver: On the Use of Event Studies to Evaluate Economic Policy Decisions: A Note of Caution, Dezember 2012.

Nr. 81 Budzinski, Oliver; Beigi, Maryam H. A.: Competition Policy Agendas for Industrializing Countries, Mai 2013. 
Nr. 82 Budzinski, Oliver; Müller, Anika: Finanzregulierung und internationale Wettbewerbsfähigkeit: der Fall Deutsche Bundesliga, Mai 2013.

Nr. 83 Doose, Anna Maria: Methods for Calculating Cartel Damages: A Survey, Dezember 2013.

Nr. 84 Pawlowski, Tim; Budzinski, Oliver: Competitive Balance and Attention Level Effects: Theore-tical Considerations and Preliminary Evidence, März 2014.

Nr. 85 Budzinski, Oliver: The Competition Economics of Financial Fair Play, März 2014.

Nr. 86 Budzinski, Oliver; Szymanski, Stefan: Are Restrictions of Competition by Sports Associations Horizontal or Vertical in Nature?, März, 2014.

Nr. 87 Budzinski, Oliver: Lead Jurisdiction Concepts Towards Rationalizing Multiple Competition Policy Enforcement Procedures, Juni 2014.

Nr. 88 Budzinski, Oliver: Bemerkungen zur ökonomischen Analyse von Sicherheit, August 2014.

Nr. 89 Budzinski, Oliver; Pawlowski, Tim: The Behavioural Economics of Competitive Balance: Implications for League Policy and Championship Management, September 2014.

Nr. 90 Grebel, Thomas; Stuetzer, Michael: Assessment of the Environmental Performance of European Countries over Time: Addressing the Role of Carbon, September 2014.

Nr. 91 Emam, Sherief; Grebel, Thomas: Rising Energy Prices and Advances in Renewable Energy Technologies, July 2014.

Nr. 92 Budzinski, Oliver; Pannicke, Julia: Culturally-Biased Voting in the Eurovision Song Contest: Do National Contests Differ?, December 2014.

Nr. 93 Budzinski, Oliver; Eckert, Sandra: Wettbewerb und Regulierung, März 2015.

Nr. 94 Budzinski, Oliver; Feddersen, Arne: Grundlagen der Sportnachfrage: Theorie und Empirie der Einflussfaktoren auf die Zuschauernachfrage, Mai 2015.

Nr. 95 Pannicke, Julia: Abstimmungsverhalten im Bundesvision Song Contest: Regionale Nähe versus Qualität der Musik, Oktober 2015.

Nr. 96 Budzinski, Oliver; Kretschmer, Jürgen-Peter: Unprofitable Horizontal Mergers, External Effects, and Welfare, October 2015. 
Nr. 97 Budzinski, Oliver; Köhler, Karoline Henrike: Is Amazon The Next Google?, October 2015.

Nr. 98 Kaimann, Daniel; Pannicke, Julia: Movie success in a genre specific contest: Evidence from the US film industry, December 2015.

Nr. 99 Pannicke, Julia: Media Bias in Women's Magazines: Do Advertisements Influence Editorial Content?, December 2015.

Nr. 100 Neute, Nadine; Budzinski, Oliver: Ökonomische Anmerkungen zur aktuellen Netzneutralitätspolitik in den USA, Mai 2016.

Nr. 101 Budzinski, Oliver; Pannicke, Julia: Do Preferences for Pop Music Converge across Countries? - Empirical Evidence from the Eurovision Song Contest, Juni 2016.

Nr. 102 Budzinski, Oliver; Müller-Kock, Anika: Market Power and Media Revenue Allocation in Professonal Sports: The Case of Formula One, Juni 2016.

Nr. 103 Budzinski, Oliver: Aktuelle Herausforderungen der Wettbewerbspolitik durch Marktplätze im Internet, September 2016.

Nr. 104 Budzinski, Oliver: Sind Wettbewerbe im Profisport Rattenrennen?, Februar 2017.

Nr. 105 Budzinski, Oliver; Schneider, Sonja: Smart Fitness: Ökonomische Effekte einer Digitalisierung der Selbstvermessung, März 2017.

Nr. 106 Budzinski, Oliver; Pannicke, Julia: Does Popularity Matter in a TV Song Competition? Evidence from a National Music Contest, April 2017.

Nr. 107 Budzinski, Oliver; Grusevaja, Marina:Die Medienökonomik personalisierter Daten und der Facebook-Fall, April 2017.

Nr. 108 Budzinski, Oliver: Wettbewerbsregeln für das Digitale Zeialter - Die Ökonomik personalisierter Daten, Verbraucherschutz und die 9.GWB-Novelle, August 2017.

Nr. 109 Budzinski, Oliver: Four Cases in Sports Competition Policy: Baseball, Judo, Football, and Motor Racing, September 2017.

Nr. 110 Budzinski, Oliver: Market-internal Financial Regulation in Sports as an Anticompetitive Institution, October 2017.

Nr. 111 Bougette, Patrice; Budzinski, Oliver; Marty, Frédéric: EXPLOITATIVE ABUSE AND ABUSE OF ECONOMIC DEPENDENCE: WHAT CAN WE LEARN FROM THE INDUSTRIAL ORGANIZATION APPROACH?, December 2017. 
Nr. 112 Budzinski, Oliver; Gaenssle, Sophia: The Economics of Social Media Stars: An Empirical Investigation of Stardom, Popularity, and Success on YouTube, Januar 2018.

Nr. 113 Gaenssle, Sophia; Budzinski, Oliver; Astakhova Daria: Conquering the Box Office: Factors, influencing Success of International Movies in Russia, Mai 2018.

Nr. 114 Budzinski, Oliver; Stöhr, Annika: Die Ministererlaubnis als Element der deutschen Wettbewerbsordnung: eine theoretische und empirische Analyse, Juli 2018.

Nr. 115 Budzinski, Oliver; Kuchinke, Björn A.: Modern Industrial Organization Theory of Media Markets and Competition Policy Implications, September 2018.

Nr. 116 Budzinski, Oliver; Lindstädt-Dreusicke, Nadine: The New Media Economics of Video-on-Demand Markets: Lessons for Competition Policy, Oktober 2018.

Nr. 117 Budzinski, Oliver; Stöhr, Annika: Competition Policy Reform in Europe and Germany - Institutional Change in the Light of Digitization, November 2018. 